\title{
Employee Voice, Communication Formality, and Employee Engagement: Is There a "New Normal" for Internal Communication in China?
}

\author{
Peter Wilson Cardon ${ }^{1}$, Min Feng ${ }^{2}$, Haibing $\mathrm{Ma}^{3}$, Qinghua $\mathrm{Ma}^{4}$ \\ ${ }^{1}$ University of Southern California, California, LA, USA \\ ${ }^{2}$ Shanghai University of International Business and Economics, Shanghai, China \\ ${ }^{3}$ Leapln Information Technology, Co., Ltd, Shanghai, China \\ ${ }^{4}$ DeepBlue Technology Co., Ltd, Shanghai, China
}

Objectives: The purpose of this paper is (a) to examine the relationship between employee voice and management receptiveness with employee engagement; (b) to explore changes in internal vertical communication during the COVID-19 pandemic; and (c) to examine how less formal communication influences employee engagement.

Methods: A survey of 344 Chinese professionals in the Shanghai region was conducted to measure employee voice; management receptiveness; internal vertical communication via DingTalk, WeChat, online meetings, and face-to-face (F2F) meetings; and use of informal communication (frequency of WeChat Moments between managers and employees). ANOVA analysis was used to compare changes across the three time periods, and hierarchical regression analysis was used to explore predictors of employee engagement.

Results: Across the pandemic, managers increased their communication with employees via DingTalk and online meetings but decreased their communication with employees via F2F meetings. Employee voice and management receptiveness were the most significant predictors of employee engagement. Perceptions of employee voice grew significantly from the pre-COVID period until the present. The increased sharing and liking of WeChat Moments among managers and employees significantly predicted higher employee engagement.

Conclusions: This is the first known study to explore the connection between employee voice and management receptiveness with employee engagement in the Chinese context. It also explores how two communication platforms, DingTalk and WeChat, with similar affordances are used with varying amounts of formality in the workplace. It highlights how the use of WeChat Moments, an informal form of communication, drives higher engagement.

Key Words: Employee Voice, Management Receptiveness, Employee Engagement, Communication Media, Social Networking

Received: Mar 21, 2021 Revised: Jun 28, 2021 Accepted: Jul 15, 2021

Corresponding author: Peter Wilson Cardon

Department of Business Communication, Marshall School of Business, University of Southern California, 3660 Trousdale Parkway, Los Angeles, CA 900890444, USA

Tel: +1-213-740-0133, E-mail: cardon@marshall.usc.edu

This is an Open Access article distributed under the terms of the Creative Commons Attribution Non-Commercial License (http://creativecommons.org/licenses/by-nc/4.0/) which permits unrestricted non-commercial use, distribution, and reproduction in any medium, provided the original work is properly cited.

Copyright $\odot 2021$ Korean Association for Business Communication. 


\section{Introduction}

The COVID-19 pandemic has dramatically influenced the nature of work. Most businesses, at least temporarily, required all office employees to work remotely. This massive disruption led to unprecedented use of virtual communication tools. Many businesses have no immediate intentions of bringing employees back to the office. Companies such as Google have a suggested return date of October 2021 but may push it back further. While many businesses are at least on a limited fashion bringing employees back to the office, many experts suggest the COVID pandemic may permanently alter the nature of work, with many suggesting a "new normal" that involves a blended, more technology-mediated approach to internal communication.

Scholars suggest that the new blended approach to internal communication requires extra care and compassion, particularly in these uncertain times, from leaders and managers (Gibson, 2020). Further, scholars suggest that new approaches to internal communication are necessary to help employees feel comfortable expressing their views in a technology-mediated environment (Cardon, Huang, \& Power, 2019). One challenge in fostering a higher sense of employee voice is that there are fewer opportunities for less formal communication. Historically, the office allows richer, in-person encounters that include casual, "water cooler" conversations. These more casual conversations build relationships and lead to more open expression of ideas (McAlpine, 2018).

While the COVID pandemic is not over, China has currently returned to "normal" work routines much faster than most countries. After a peak of cases and lockdown measures in late January through March 2020, most employees returned to work in subsequent months. For the purpose of this project, we label the early January period as pre-COVID, the March time frame as mid-COVID (the height of disturbances to work routines), and September as post-COVID (we recognize there may be additional COVID-related disruptions and that other regions of the world continue to have major outbreaks).

Researchers and consultants have suggested internal communication in China changed in several important ways over the course of the COVID pandemic. First, managers engaged their employees with more open and caring communication. Second, employees and managers increased their use of digital communication tools (Narayandas, Hebbar, \& Li, 2020; Pan, Yang, Yu, \& Zhang, 2020). Among the most popular communication platforms include DingTalk and WeChat, and most Chinese professionals use both platforms for work purposes. While DingTalk and WeChat involve nearly identical communication affordances, DingTalk is considered more formal than WeChat. Thus, they serve as a way to identify how the perceived formality of media influence use and impacts. The purposes of this study include the following: (a) explore how employee voice, manager receptiveness, and employee engagement have changed before, during, and after the pandemic; (b) explore how the frequency of use of various communication media has changed before, during, and after the pandemic; and (c) explore how employee voice, management receptiveness, frequency of media use, and formality of communication influence employee engagement. This research highlights the links between employee voice and manager receptiveness in a new cultural context: China. It also highlights the potential importance of informal online communication to foster higher engagement. This is particularly noteworthy in a professional environment that relies increasingly on online communication.

\section{Literature Review}

Researchers and scholars suggest internal communication in Chinese organizations has changed due to COVID with higher focus on open, direct, and caring approaches (Narayandas et al., 2020; Pan et al., 2020). We address this proposition in terms of employee voice and manager receptiveness. They also suggest internal communication in Chinese organizations has become more digital. We address this proposition in terms of communication media and related formality.

\section{Employee Voice, Manager Receptiveness, and Employee} Engagement

Abundant literature over the past decades has established the importance of employee engagement and its relation to employee satisfaction, employee productivity, organizational commitment, customer satisfaction, and profitability (Harter, Schmidt, \& Hayes, 2002; Macey \& Schneider, 2008; Saks, 2006). Some survey work during the first few months of the COVID crisis suggested that employee engagement in the USA rose among remote employees. Many experts believe it is the caring and transparent response of employers that has driven this change. Yet, it's not clear whether this rise in engagement is sustainable (Emmett, Schrah, Schrimper, \& Wood, 2020; Harter, 2020). It's also not certain whether engagement levels in China rose during this period.

Only recently, however, have scholars turned their attention to the role that internal communication has on engagement (Gruman \& Saks, 2014; Ruck \& Welch, 2012; Ruck, Welch, \& Menara, 2017; Welch, 2011). Ruck and Welch (2012) pioneered research that theorized the importance of employee-centric communication processes on employee engagement. They 
reviewed a dozen prominent communication audits and demonstrated that they typically focus on management-centric communication processes. Building on this work, Ruck et al. (2017) conducted the most comprehensive study on this issue by surveying over 2,000 professionals in the United Kingdom. They found that upward employee voice and senior manager receptiveness led to higher employee engagement. The research suggests the critical importance of focusing on employee voice and senior management receptiveness as part of an internal communication strategy. Their study also showed significant room for improvement as average scores for employee voice and management receptiveness were generally mediocre.

No known studies examine the relationship between employee voice and engagement in China, although Nawakitphaitoon and Zhang (2020) showed that employee voice has a positive impact on employees' job satisfaction. Researchers note that employee voice emerges from a Western paradigm and may have unique manifestations in the more hierarchical Chinese culture (Holley, Wu, \& Avey, 2019). The existing research about employee voice in China has primarily focused on the relationship between leadership style and employee voice behaviors. For example, leader trustworthiness led to higher employee voice (Holley et al., 2019). Authoritarian leadership styles have been associated with lower employee voice (Li \& Sun, 2015). More specifically, authoritarian paternalistic leadership behaviors have led to lower employer voice, whereas benevolent and moral paternalistic leadership behaviors led to higher employee voice (Jia, Zhou, Zhang, \& Jiang, 2020; Zhang, Huai, \& Xie, 2015). Interestingly, guanxi relationships have not been associated with higher employee voice. For example, Yan and Xiao (2016) found that although servant leadership leads to higher employee voice, guanxi relationships negatively moderate voice behavior. In other words, guanxi relationships likely involve so much loyalty that subordinates are less likely to speak up.

Researchers and consultants have examined some of the workplace changes that have occurred in China due to COVID. With survey work of over 300 senior-level executives, Narayandas et al. (2020) reported Chinese businesses have emphasized more open and direct communication; encouraged more upward communication; and promoted more tolerance, patience, and empathy. Further, in another survey of 1,300 China-based executives, middle managers, and frontline staff, Pan et al. (2020) reported managers were taking extra efforts to demonstrate care for colleagues. Thus, we propose the following hypotheses over the COVID time period:

- Hypothesis 1a: Perceptions of upward employee voice rose during the COVID pandemic.

- Hypothesis 1b: Perceptions of management receptiveness rose during the COVID pandemic.

- Hypothesis 1c: Perceptions of employee engagement rose during the COVID pandemic.

- Further, we expect that the relationships between employee voice and management receptiveness with employee engagement are similar to those in a study of U.K. professionals by Ruck et al. (2017). Thus, we hypothesize the following:

- Hypothesis 2a: Upward employee voice positively influences employee engagement.

- Hypothesis 2b: Management receptiveness positively influences employee engagement.

\section{Communication Media and Formality of Internal}

\section{Communication}

A recent survey worked has reported the increased use of digital communication media for internal communication between managers and employees. Narayandas et al. (2020) reported that Chinese businesses prioritized DingTalk and WeChat more than email and increased the use of online meetings. Pan et al. (2020) reported that many professionals were using new media to collaborate with colleagues. As a result, we focus specifically on four communication media/channels: DingTalk, WeChat, online meetings (e.g., Zoom, Tencent Meetings), and face-toface (F2F) meetings. DingTalk and WeChat are communication and collaboration platforms that have similarities with Slack, a well-known American team messaging collaboration platform. Professionals can message, share pictures and videos, collaborate on files, and engage in a variety of project management practices. DingTalk and WeChat have achieved far more aggregate popularity than Slack. For example, DingTalk has 200 million active users in corporate environments compared to 12 million active users for Slack in corporate environments $(\mathrm{Li}$, 2020). We hypothesize the following regarding internal communication by Chinese managers to their employees:

- Hypothesis 3a: The use of DingTalk will increase during the COVID pandemic.

- Hypothesis 3b: The use of WeChat will increase during the COVID pandemic.

- Hypothesis 3c: The use of online meetings will increase during the COVID pandemic.

- Hypothesis 3d: The use of F2F meetings will decrease during the COVID pandemic.

Interestingly, although DingTalk and WeChat effectively have similar communication affordances, DingTalk is perceived as more formal. Formality of communication typically involves several factors. Formal communication is generally associated with official company meetings and communication channels. It generally involves protocols and agendas. Embedded in the 
communication, there is typically a clear hierarchy or process for decision making. Formal communication has been associated with stronger performance at a company and team level. Informal communication typically involves side conversations among employees (sometimes referred to as gossip and grapevine conversations). It is often associated with more social and non-business conversations. Similarly, it is often less planned and more spontaneous. It often occurs outside of standard communication channels. Informal communication is associated with stronger personal relationships, which in turn often support better business outcomes. In practice, the right balance between formal and information communication often leads to positive task and relationship outcomes (Andrén, Sanne, \& Linell, 2010; Johnson, Donohue, Atkin, \& Johnson, 1994; Kyriazis \& Massey, 2008; Robinson \& Thelen, 2018; Temby, Sandall, Cooksey, \& Hickey, 2017; Tenhiala \& Salvador, 2018).

Several theories address how media choice influences communication, including media richness theory (Daft \& Lengel, 1986), channel expansion theory (Carlson \& Zmud, 1999), and media synchronicity theory (MST) (Dennis \& Valacich, 1999; Dennis, Fuller, \& Valacich, 2008; Maruping \& Agarwal, 2004). These theories typically focus on the affordances of various technologies and recommend technologies that match the right affordances with the goal of the communication. Some research addresses the formality professionals use when communicating via certain communication media (Peterson, Hohensee, \& Xia, 2011). These studies typically employ models of formality, such as that of Brown and Levinson (1987) with their politeness theory. These studies tend to compare media with various affordances (e.g., in-person conversation versus phone call, texting versus email). However, existing research does not compare media with nearly identical affordances, such as those of DingTalk and WeChat. As a result, we adopt an orientation towards this project of media symbolism, which focuses less on affordances and more so on the symbolic traits of the media (Treviño, Webster, \& Stein, 2000). As far as we know, no studies compare the perceived formality of communication media with similar technology affordances.

In the case of DingTalk and WeChat, the media symbolism of DingTalk as more formal and WeChat as less formal can be traced to their origins. DingTalk was originally developed as an all-in-one mobile workstation for professional communication. It was built on an assumption of hierarchical administration in the workplace. WeChat, on the other hand, was originally developed as a social tool for family and friends with an implied flat structure. Over time, DingTalk has maintained its function as a professional communication platform but incorporated various social features. WeChat has evolved to include many functions for the workplace. While the two platforms now allow many of the same workplace functions, WeChat is symbolically viewed as more social and flat, whereas DingTalk is symbolically viewed as more professional and hierarchical.

The formality of communication media is of particular importance in the COVID era. As the use of virtual technologies in the workplace grows, views of and attitudes toward these tools are evolving. Yet, it is not merely a technical phenomenon. In this uncertain period, employees are developing changing expectations of what they view as leadership and humane organizational cultures. Gibson (2020) recently developed a "Care in Connecting" model that addresses these issues. Care in connecting involves three principles: inclusion, co-presence, and vitality. Inclusion involves ensuring that diverse voices are heard online. Co-presence involves choosing technologies that help provide a sense of psychological proximity. Vitality involves a sense of energy and enthusiasm in online environments.

In our study, we focus specifically on the use of WeChat Moments, a commonly used feature that Wechat less formal than DingTalk. WeChat Moments are posts that may include text messages, pictures, and videos that are limited to verified friends. Moments are typically only shared among closer friends and involve a high level of personal information. Among colleagues, WeChat Moments often blur the boundaries of work and personal interactions, and scholars and practitioners suggest they contribute to the development of guanxi relationships (Shao \& Pan, 2019; Zhang, 2018). Among Chinese adults, the use of WeChat Moments and received likes are significantly related to self-esteem, whereas the frequency of status updates is negatively associated with self-esteem. Overall, higher use of WeChat Moments increases levels of social capital and self-esteem (Wang, Nie, Li, \& Zhou, 2018). Given the fact that WeChat moments have been associated with self-esteem and social capital, we hypothesize the following:

- Hypothesis 4: The increased use of WeChat moments for internal communication between managers and employees will lead to higher employee engagement.

\section{Methods}

To test our hypotheses, we developed a survey to administer to Chinese professionals. The survey was developed to measure upward employee voice, senior manager receptiveness, employee engagement, communication channel frequency of use, formality of WeChat, and various demographic variables. The survey items are provided in the appendix 1. Participants reported all items for three times: January 2020 (pre-COVID), March 2020 (mid-COVID), and September 2020 (post-COVID). We ad- 
opted measures from Ruck et al. (2017) for employee voice that evaluated the degree to which employees feel comfortable sharing their views, ideas, and criticism to managers $\left(\alpha^{\text {pre-Covid }}=.87\right.$; $a^{\text {mid-Covid }}=.88 ; a^{\text {post-Covid }}=.87$ ). We also adopted measures from Ruck et al. (2017) for senior manager receptiveness that focuses on the degree to which managers seek the views of employees, respond to employee suggestions, and involve employees in final decisions ( $\alpha^{\text {pre-Covid }}=.85 ; \alpha^{\text {mid-Covid }}=.83 ; \alpha^{\text {post-Covid }}=.85$ ). We used a single item for engagement (i.e., "I am highly engaged in my job") that has been shown to possess high validity and correlates closely with a variety of workplace engagement measures (Kulikowski, 2019). We assessed frequency of various communication channels in similar form to several related studies (Cardon \& Marshall, 2015; Men \& Hung-Baesecke, 2015). Regarding the formality of WeChat, we developed a three-item measure that assessed the degree to which managers and employees share and like personal content via WeChat Moments ( $a^{\text {pre-Covid }}=.70 ; a^{\text {mid- }}$ Covid $=.72 ; \alpha^{\text {post-Covid }}=.70$ ).

We piloted our survey in late August 2020 with 42 respondents. After reviewing feedback from some of the respondents and analyzing the results, we then administered the survey with minor modifications during the first week of September 2020. Altogether, 344 professionals in the Shanghai area completed the survey. Men comprised $50.6(n=169)$ percent of the sample, with women at 47.9 percent $(n=160)$ and 1.5 percent $(n$ $=5)$ unknown. Roughly 53.6 percent $(n=179)$ were frontline staff, 25.4 percent $(n=85)$ were middle managers, 8.1 percent $(n=27)$ were senior managers, and $12.9(n=43)$ percent were in other roles. Roughly 3.9 percent $(n=13)$ were 24 years or younger, 32.9 percent $(n=110)$ were 25 to 30 years old, 31.1 percent $(n=104)$ were 31 to 40 years old, 24.6 percent $(n=82)$ were 41 to 50 years old, 6.9 percent $(n=23)$ were over 50 years old, and .6 percent $(n=2)$ were of unknown age.

\section{Results}

On the whole, Chinese professionals reported quite high up- wards employee voice, with means generally close to four (on a 5-point Likert scale), corresponding with a "satisfied" rating. Further, Hypothesis la was confirmed with a significant rise in employee voice from pre-COVID and mid-COVID periods to the post-COVID period. Management receptiveness showed slightly-above average ratings with means around 3.5, suggesting an overall rating of between "neutral" and "good." While the mean scores for post-COVID receptiveness were higher than pre-COVID and mid-COVID ratings, these differences were not statistically significant. Thus, Hypothesis $1 \mathrm{~b}$ was not confirmed. Finally, employment engagement was on average fairly strong with mean ratings near four. Differences across the time periods did not reveal any significant statistical differences, so Hypothesis 1c was not confirmed. See Table 1 for additional details.

As far as the use of communication media/channels, three (H3a, H3c, H3d) of the four hypotheses were confirmed, with DingTalk and online meetings increasing in use during the height of COVID, whereas the use of F2F meetings declined. Interestingly, the use of WeChat remained the same, so $\mathrm{H} 3 \mathrm{~b}$ was not confirmed. Overall, WeChat was used the most frequently for internal communication between managers and employees. With a mean around four, the frequency of this form of internal communication averages to a daily basis. DingTalk and online meetings remain less used for internal communication between managers and employees. See Table 2 for additional details.

To explore relationships with employee engagement, we conducted a hierarchical regression analysis with engagement as the dependent variable at each time period: pre-COVID, mid-COVID, and post-COVID. Management receptiveness and employee voice (with the exception of the Pre-COVID period) were strong predictors of employee engagement, so $\mathrm{H} 2 \mathrm{a}$ and $\mathrm{H} 2 \mathrm{~b}$ were confirmed. Collectively, receptiveness and voice accounted for roughly 27.5 percent of the variance in the post-COVID stage (almost identical to the work of Ruck et al. [2017] in a study of U.K. professionals). Among demographic variables, women were significantly less likely to report higher

Table 1. ANOVA tests of significance for Pre-COVID, Mid-COVID, and Post-COVID measures of employee voice, manager receptiveness, and engagement

\begin{tabular}{|c|c|c|c|c|c|c|c|c|c|c|}
\hline \multirow[t]{2}{*}{ Variable } & \multicolumn{3}{|c|}{ January 2020} & \multicolumn{3}{|c|}{ March 2020} & \multicolumn{3}{|c|}{ September 2020} & \multirow[t]{2}{*}{$F$-value } \\
\hline & $n$ & $M$ & $S D$ & $n$ & $M$ & $S D$ & $n$ & $M$ & $S D$ & \\
\hline Voice & 334 & 3.91 & .82 & 333 & 3.84 & .90 & 333 & 4.02 & .73 & $4.15^{*}$ \\
\hline Receptiveness & 334 & 3.48 & .90 & 333 & 3.55 & .90 & 333 & 3.61 & .88 & 1.53 \\
\hline Engagement & 333 & 3.90 & .84 & 331 & 3.89 & .85 & 332 & 3.93 & .82 & 1.10 \\
\hline
\end{tabular}

Note. $M$, mean; $S D$, standard deviation.

${ }^{*} p<.05$. 
Table 2. ANOVA tests of significance for Pre-COVID, Mid-COVID, and Post-COVID frequency of communication via various media

\begin{tabular}{|c|c|c|c|c|c|c|c|c|c|c|}
\hline \multirow[t]{2}{*}{ Variable } & \multicolumn{3}{|c|}{ January 2020} & \multicolumn{3}{|c|}{ March 2020} & \multicolumn{3}{|c|}{ September 2020} & \multirow[t]{2}{*}{ F-value } \\
\hline & $n$ & $M$ & $S D$ & $n$ & $M$ & $S D$ & $n$ & $M$ & $S D$ & \\
\hline Ding talk & 325 & 6.02 & 1.52 & 324 & 5.15 & 1.98 & 323 & 5.24 & 2.04 & $21.03^{* *}$ \\
\hline WeChat & 324 & 4.20 & 1.59 & 325 & 4.02 & 1.57 & 324 & 4.23 & 1.69 & 1.55 \\
\hline Online Mtgs & 325 & 6.02 & 1.52 & 326 & 5.48 & 1.43 & 326 & 5.73 & 1.51 & $10.72^{* * *}$ \\
\hline F2F Mtgs & 327 & 4.58 & 1.52 & 328 & 5.76 & 1.79 & 329 & 4.80 & 1.72 & $46.72^{* *}$ \\
\hline Moments & 325 & 2.31 & 0.49 & 325 & 2.31 & 0.51 & 325 & 2.32 & 0.50 & 0.13 \\
\hline
\end{tabular}

Note. $M$, mean; SD, standard deviation; F2F, face-to-face; $M$ tgs, meetings. ${ }^{* *} p<.01$.

engagement scores at each time period. Older employees were significantly less likely to report higher engagement in the preCOVID and mid-COVID periods, although this became statistically insignificant for the post-COVID stage. The frequency of using various communication media, after controlling for voice and receptiveness, did not significantly impact engagement. The one exception is that in the pre-COVID period, the increased use of DingTalk predicted less engagement. Finally, the sharing of WeChat Moments between managers and employees was a significant predictor of engagement in all time periods, thus confirming $\mathrm{H} 4$. The more frequent sharing and liking of WeChat Moments corresponded with higher engagement. See Table 3 for more details.

\section{Discussion}

This research shows the strong connection between management receptiveness and employee voice with employee engagement. Based on standardized regression coefficients, management receptiveness exerts the strongest impact on employee engagement. This effect was enduring before, during, and after the COVID crisis. Given the outsize impact of management receptiveness, we recommend prioritized attention to this variable in future studies of internal communication and employee engagement in China. Given the high power-distance nature of Chinese culture and recent work on paternalistic leadership styles in many recent studies (e.g., Jia et al., 2020; Zhang, Huai, $\&$ Xie, 2015), exploring the ways in which management receptiveness is practiced would fill an important need. In practice, this demonstrates the need for managers and internal communicators to focus on responding to employee views and suggestions as the foundation for internal communication strategies.

This research also shows the importance of employee voice. There was a significant increase in perceptions of employee voice from the pre-COVID period to the post-COVID period. Interestingly, employee voice was not a significant predictor of employee engagement in the pre-COVID period and then be- came significant in the mid-COVID and post-COVID time periods. Its impact based on standardized regression coefficients grew in importance from the mid-COVID to the post-COVID time period. It's possible that because Chinese managers have adopted a more open, transparent, and caring communication environment in the COVID period (e.g., Narayandas et al., 2020; Pan et al., 2020), employees now feel a higher sense of employee voice and expect it as part of their organizational cultures. Additional research should address what may be shifting expectations in employee voice and whether these changes are temporary or enduring. Similar to management receptiveness, the large impact on employee voice on employee engagement suggests managers and internal communicators should emphasize a robust, dynamic, two-way communication environment.

One of the more intriguing findings is the influence of sharing and liking of WeChat Moments between managers and employees. This use of informal, personal communication is another important predictor of employee engagement. It's possible the sharing of liking of WeChat Moments between managers and employees contributes to their self-esteem in social capital in organizational settings. Yet, the mechanisms for how this occurs require additional research. Further, future research should explore the degree to which the use of WeChat Moments contribute to guanxi relationships (Chen, Friedman, Yu, Fang, \& $\mathrm{Lu}, 2009)$ with related impacts on engagement. Some research suggests that guanxi relationships may not necessarily lead to higher engagement or improved work outcomes (Shao \& Pan, 2019; Yan \& Xiao, 2016; Zhang, 2018). More recent research aligns with the results in this study. Guo, Lee, and Kramer (2021) found that WeChat moments allowed new employees to observe their new colleagues and learn more about how to build relationships with them. It will be important to research both the productive and counterproductive ways in which the use of WeChat Moments in internal communication affect employee attitudes and behaviors.

The fact that WeChat moments have a significant influence on employee engagement suggests more research is needed that 
Table 3. Hierarchical regression for employee engagement before, during, and after the COVID pandemic

\begin{tabular}{|c|c|c|c|}
\hline Variable & $\begin{array}{l}\text { Pre-COVID } \\
(J a n 2020)\end{array}$ & $\begin{array}{c}\text { Mid-COVID } \\
\text { (March 2020) }\end{array}$ & $\begin{array}{l}\text { Post-COVID } \\
\text { (Sept 2020) }\end{array}$ \\
\hline \multicolumn{4}{|l|}{ Step 1} \\
\hline Employee voice & 0.093 & $0.114^{*}$ & $0.175^{* *}$ \\
\hline Managerial receptiveness & $0.385^{* *}$ & $0.411^{* *}$ & $0.380^{* *}$ \\
\hline$F$ & 0.247 & 0.269 & 0.275 \\
\hline$R^{2}$ & $49.657^{* *}$ & $56.145^{* *}$ & $57.578^{* *}$ \\
\hline \multicolumn{4}{|l|}{ Step 2} \\
\hline Gender & $-0.130^{* *}$ & $-0.098^{*}$ & $-0.140^{* *}$ \\
\hline Age & $0.153^{* *}$ & $0.120^{*}$ & 0.060 \\
\hline Organizational tenure & 0.001 & -0.002 & -0.025 \\
\hline Return to work & - & - & 0.106 \\
\hline$F$ & $24.569 * *$ & $25.418^{* *}$ & $21.725^{* *}$ \\
\hline$R^{2}$ & 0.291 & 0.296 & 0.304 \\
\hline$\Delta R^{2}$ & 0.044 & 0.027 & 0.029 \\
\hline \multicolumn{4}{|l|}{ Step 3} \\
\hline Ding talk frequency & $-0.115^{*}$ & -0.052 & -0.072 \\
\hline WeChat frequency & -0.039 & 0.035 & 0.030 \\
\hline Online conference frequency & 0.032 & -0.049 & 0.052 \\
\hline Face-to-face meetings Frequency & 0.046 & -0.022 & -0.011 \\
\hline WeChat moments frequency & $0.135^{*}$ & $0.132^{*}$ & $0.117^{*}$ \\
\hline$F$ & $13.659 * *$ & $13.830^{* *}$ & $12.447^{* * *}$ \\
\hline$R^{2}$ & 0.316 & 0.318 & 0.318 \\
\hline$\Delta R^{2}$ & 0.025 & 0.022 & 0.014 \\
\hline
\end{tabular}

Note. All standardized regression coefficients are from the final step in the analyses $(n=307)$.

${ }^{*} p<.05,{ }^{* *} p<.01$.

specifically focuses on how informal communication can influence manager-employee relationships and engagement in online work environments. Guo et al. (2021) found that new employees who used informal communication, such as WeChat, were better able to onboard and build social relationships with colleagues. These studies have emerged at a time in which because of remote work arrangements, millions of professionals lack traditional opportunities for informal communication in the form of "water cooler" conversations. By examining technologies that not only afford but also symbolize informality in online settings, researchers can learn more about how they tools can potentially simulate traditional office environments.

Generally, the frequency with which managers communicate with employees via DingTalk, WeChat, online meetings, and F2F meetings did not appear to impact engagement above and beyond the impacts of employee voice and management receptiveness. Yet, it does appear there is more frequent use of less formal media, such as with WeChat, than there is more formal media, such as DingTalk and online meetings. Additional research is needed to explore the best mix of formal and informal forms of communication media. Specifically, additional research should focus on the contexts in which DingTalk, as a more formal media, is more productive versus the contexts in which WeChat, a less formal media, is more productive. Similarly, additional research is needed about the extent to which WeChat and DingTalk contribute to blurred boundaries between professional and personal lives.

Finally, we recommend further research about cross-cultural comparisons and analysis of employee voice and management receptiveness. Historically, cross-cultural experts have suggested employees in individualist and low power distance societies, such as most English-speaking Western countries, tend to feel empowered to offer their views in comparison to employees in collectivist and high power distance societies, such as China and most East Asian societies. Yet, employee voice ratings in this Chinese sample were quite high. Further, this research should examine the degree to which use of informal and formal communication media influence cultural norms and values. 


\section{Conclusion}

The purpose of this study was (a) to examine the relationship between employee voice and management receptiveness with employee engagement; (b) to explore changes in internal vertical communication during the COVID-19 pandemic; and (c) to examine how less formal communication influences employee engagement. Surveys of Chinese professionals showed that across the pandemic, managers increased their communication with employees via DingTalk and online meetings but decreased their communication with employees via face-toface meetings. Employee voice and management receptiveness were the most significant predictors of employee engagement. Perceptions of employee voice grew significantly from the preCOVID period until the present. The increased sharing and liking of WeChat Moments among managers and employees significantly predicted higher employee engagement.

\section{References}

Andrén, M., Sanne, J. M., \& Linell, P. (2010). Striking the balance between formality and informality in safety-critical communication: Train traffic control calls. Journal of Pragmatics, 42(1), 220-241.

Brown, P., \& Levinson, S. C. (1987). Politeness: Some universals in language usage. Cambridge, UK: Cambridge University Press.

Cardon, P. W., Huang, Y., \& Power, G. (2019). Leadership communication on internal digital platforms, emotional capital, and corporate performance: The case for leader-centric listening. International Journal of Business Communication. Advance online publication. doi: 10.1177/2329488419828808

Cardon, P. W., \& Marshall, B. (2015). The hype and reality of social media use for work collaboration and team communication. International Journal of Business Communication, 52(3), 273-293.

Carlson, J. R., \& Zmud, R. W. (1999). Channel expansion theory and the experiential nature of media richness perceptions. Academy of Management Journal, 42(2), 153-170.

Chen, Y., Friedman, R., Yu, E., Fang, W. H., \& Lu, X. (2009). Supervisor-subordinate Guanxi: Developing a three-dimensional model and scale. Management and Organization Review, 5(3), 375-399.

Daft, R. L., \& Lengel, R. H. (1986). Organizational information requirements, media richness and structural design. Management Science, 32(5), 554-571.

Dennis, A. R., Fuller, R. M., \& Valacich, J. S. (2008). Media, tasks, and communication processes: A theory of media synchronicity. MIS Quarterly, 32(3), 575-600.

Dennis, A. R., \& Valacich, J. S. (1999). Rethinking media richness: Towards a theory of media synchronicity. Proceedings of the 32nd
Hawaii International Conference on System Sciences. Hawaii, HI.

Emmett, J., Schrah, G., Schrimper, M., \& Wood, A. (2020, June 29). COVID-19 and the employee experience: How leaders can seize the moment. McKinsey. Retrieved from https://www.mckinsey. com/business-functions/organization/our-insights/covid-19-andthe-employee-experience-how-leaders-can-seize-the-moment

Gibson, C. (2020). From "social distancing" to "care in connecting": An emerging organizational research agenda for turbulent times. Academy of Management Discoveries, 6(2), 165-169.

Gruman, J. A., \& Saks, A. M. (2014). Being psychologically present when speaking up: Employee voice engagement. In A. Wilkinson, J. Donaghey, T. Dundon, \& R. B. Freeman (Eds.), Handbook of research on employee voice (pp. 455-476). Cheltenhamm, UK: Edward Elgar.

Guo, Y., Lee, S. K., \& Kramer, M. W. (2021). "We work in international companies": Affordances of communication media in Chinese employees' organizational socialization. Communication Studies, 72(5), 788-806.

Harter, J. (2020, May 29). Employee engagement continues historic rise amid coronavirus. Gallup. Retrieved from https://www. gallup.com/workplace/311561/employee-engagement-continues-historic-rise-amid-coronavirus.aspx

Harter, J. K., Schmidt, F. L., \& Hayes, T. L. (2002). Business-unit-level relationship between employee satisfaction, employee engagement, and business outcomes: A meta-analysis. Journal of Applied Psychology, 87(2), 268-279.

Holley, E. C., Wu, K., \& Avey, J. B. (2019). The impact of leader trustworthiness on employee voice and performance in China. Journal of Leadership \& Organizational Studies, 26(2), 179-189.

Jia, J., Zhou, S., Zhang, L., \& Jiang, X. (2020). Exploring the influence of paternalistic leadership on voice behavior: A moderated mediation model. Employee Relations, 42(2), 542-560.

Johnson, J. D., Donohue, W. A., Atkin, C. K., \& Johnson, S. (1994). Differences between formal and informal communication channels. The Journal of Business Communication, 31(2), 111-122.

Kulikowski, K. (2019). Measurement of work engagement with a single-item measure. Polish Psychological Bulletin, 49(4), 406-415.

Kyriazis, E., \& Massey, G. (2008). The effects of formal and informal communication between marketing and $\mathrm{R} \& \mathrm{D}$ managers during new product development projects. Proceedings of the Academy of Marketing Conference (pp. 1-10). Aberdeen, Scotland.

Li, J. (2020, March 10). High-the shackles: What is DingTalk, Alibaba's Slack equivalent that quarantined kids in China hate? Quartz. Retrieved from https://qz.com/1814937/what-is-dingtalk-the-alibaba-app-that-quarantined-kids-in-china-hate/

Li, Y., \& Sun, J. M. (2015). Traditional Chinese leadership and employee voice behavior: A cross-level examination. The Leadership Quarterly, 26(2), 172-189. 
Macey, W. H., \& Schneider, B. (2008). The meaning of employee engagement. Industrial and Organizational Psychology, 1(1), 3-30.

Maruping, L. M., \& Agarwal, R. (2004). Managing team interpersonal processes through technology: A task-technology fit perspective. Journal of Applied Psychology, 89(6), 975-990.

McAlpine, K. L. (2018). Flexible work and the effect of informal communication on idea generation and innovation. Academy of Management Proceedings (Vol. 2018, No. 1). Briarcliff Manor, NY.

Men, L. R., \& Hung-Baesecke, C. F. (2015). Engaging employees in China: The impact of communication channels, organizational transparency, and authenticity. Corporate Communications: An International Journal, 20(4), 448-467.

Narayandas, D., Hebbar, V., \& Li, L. (2020, June 05). Lessons from Chinese companies' response to Covid-19. Harvard Business Review. Retrieved from https://hbr.org/2020/06/lessons-fromchinese-companies-response-to-covid-19

Nawakitphaitoon, K., \& Zhang, W. (2020). The effect of direct and representative employee voice on job satisfaction in China: Evidence from employer-employee matched data. International Journal of Human Resource Management. Advance online publication. doi: 10.1080/09585192.2020.1744028

Pan, L., Yang, B., Yu, T., \& Zhang, H. (2020). Re-energizing through the epidemic: Stories from China. Kerala, India: McKinsey.

Peterson, K., Hohensee, M., \& Xia, F. (2011). Email formality in the workplace: A case study on the Enron corpus. Proceedings of the Workshop on Language in Social Media (LSM 2011) (pp. 86-95). Portland, OR.

Robinson, K. L., \& Thelen, P. D. (2018). What makes the grapevine so effective? An employee perspective on employee-organization communication and peer-to-peer communication. Public Relations Journal, 12(2), 1-20.

Ruck, K., \& Welch, M. (2012). Valuing internal communication; management and employee perspectives. Public Relations Review, 38(2), 294-302.
Ruck, K., Welch, M., \& Menara, B. (2017). Employee voice: An antecedent to organisational engagement? Public Relations Review, 43(5), 904-914.

Saks, A. M. (2006). Antecedents and consequences of employee engagement. Journal of Managerial Psychology, 21(7), 600-619.

Shao, Z., \& Pan, Z. (2019). Building Guanxi network in the mobile social platform: A social capital perspective. International Journal of Information Management, 44, 109-120.

Temby, O., Sandall, J., Cooksey, R., \& Hickey, G. M. (2017). Examining the role of trust and informal communication on mutual learning in government: The case of climate change policy in New York. Organization \& Environment, 30(1), 71-97.

Tenhiala, A., \& Salvador, F. (2018). When communication should be formal. MIT Sloan Management Review, 60(1), 1-6.

Treviño, L. K., Webster, J., \& Stein, E. W. (2000). Making connections: Complementary influences on communication media choices, attitudes, and use. Organization Science, 11(2), 163-182.

Wang, Y., Nie, R., Li, Z., \& Zhou, N. (2018). WeChat moments use and self-esteem among Chinese adults: The mediating roles of personal power and social acceptance and the moderating roles of gender and age. Personality and Individual Differences, 131(1), 31-37.

Welch, M. (2011). The evolution of the employee engagement concept: Communication implications. Corporate Communications: An International Journal, 16(4), 328-346.

Yan, A., \& Xiao, Y. (2016). Servant leadership and employee voice behavior: A cross-level investigation in China. SpringerPlus, 5, 1595.

Zhang, M. (2018, April 6). WeChat blurs work and life in China. Medium. Retrieved from https://medium.com/@myyzhang/ wechat-blurs-work-and-life-in-china-6a4118839e29

Zhang, Y., Huai, M., \& Xie, Y. (2015). Paternalistic leadership and employee voice in China: A dual process model. The Leadership Quarterly, 26(1), 25-36. 


\section{Appendix}

Appendix 1. Survey items

1. I have opportunities to feed my views upwards to my managers.

2. There are ways for me to pass on criticisms to my managers.

3. There are ways for me to communicate my ideas to my managers.

4. My managers seek the views of employees.

5. My managers respond to suggestions from employees.

6. My managers allow employees to influence final decisions.

7. I am highly engaged in this job.

8. How often did you use the following tools to communicate with your manager/s?
a. DingTalk
b. WeChat
c. Video Conference Tools (e.g., Zoom, Tencent Meetings)
d. In-person Meetings

9. Do you allow your manager to see your WeChat Moments?

10. Do you like your Manager's WeChat Moments?

11. Does your manager like your WeChat Moments?

12. How long have you worked at your organization?

13. What best describes your return to the office?

14. Age:

15. Gender:

Survey Item Notes:

- Participants responded to all items for three time periods: January 2020 (Pre-COVID); March 2020 (Mid-COVID); September 2020 (Post-COVID) for survey items \#1 through \#11.

- Items \#1 to \#3 were for the employee voice scale from Ruck. The scale was from 1 , very dissatisfied, to 5 , very satisfied.

- Items \#4 to \#6 were for the senior manager receptiveness scale. The scale was from 1 , very poor, to 5 , very good.

- Item \#8 involved the following choices: 1 : more than once per hour; 2 : hourly; 3: every few hours; 4: daily; 5: every few days; 6: every few weeks; 7: rarely; 8: never.

- Items \#9 to \#11 involved the following choices: 1: never; 2 : sometimes; 3 : often

- Item \#13 involved the following choices: Returned to the office in March; Returned to the office in April; Returned to the office in May; Returned to the office in June; Returned to the office in July; Returned to the office in August; Remain working from home. 